Document downloaded from:

http://hdl.handle.net/10251/65417

This paper must be cited as:

Luján, JM.; Climent, H.; Pla Moreno, B.; Rivas Perea, ME.; Francois, N.; Borges Alejo, J.; Soukeur, Z. (2015). Exhaust gas recirculation dispersion analysis using in-cylinder pressure measurements in automotive diesel engines. Applied Thermal Engineering. 89:459-468. doi:10.1016/j.applthermaleng.2015.06.029.

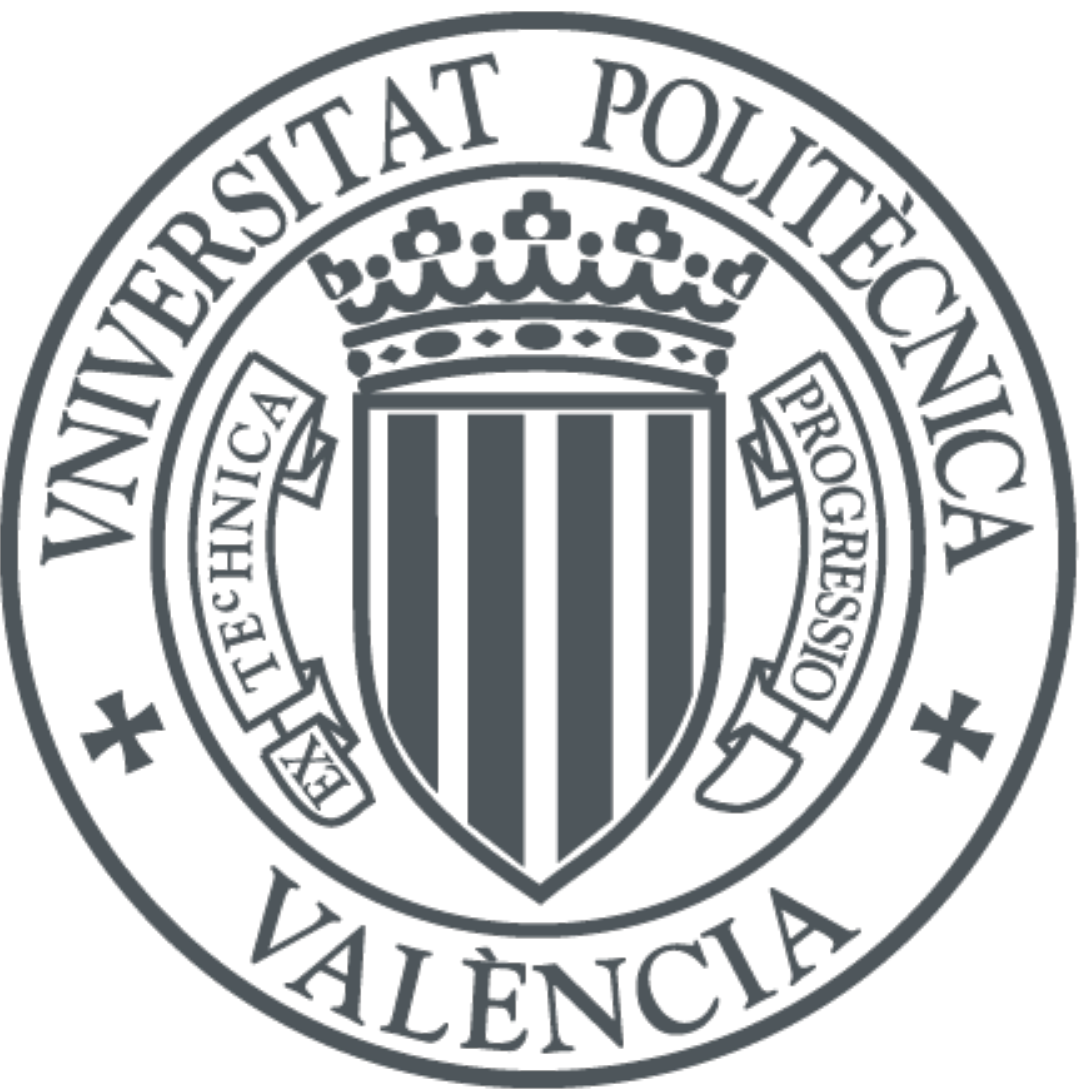

The final publication is available at

http://dx.doi.org/10.1016/j.applthermaleng.2015.06.029

Copyright Elsevier

Additional Information 


\title{
Exhaust gas recirculation dispersion analysis using in-cylinder pressure measurements in automotive diesel engines
}

\author{
José Manuel Luján, Héctor Climent", Benjamín Pla and Manuel Eduardo Rivas- \\ Perea
}

CMT Motores Térmicos, Universitat Politècnica de València, Spain

*Corresponding author: hcliment@mot.upv.es. Telephone: (+34) 9638776 50. Postal address: CMT Motores Térmicos. Universitat Politècnica de València. Camino de Vera s/n. 46022. Valencia. Spain.

\section{Nicolas-Yoan François, Jose Borges-Alejo and Zoulikha Soukeur}

Valeo Thermal Systems, R\&D Advanced Development. La Verriere, France

\begin{abstract}
Current diesel engines are struggling to achieve exhaust emissions regulations margins, in certain cases penalizing the fuel consumption. The exhaust gas recirculation (EGR) continues to be employed as a technique to reduce NOx emissions. EGR dispersion between cylinders is one important issue when a high pressure (HP) loop is used. Different techniques have been developed in order to analyze the EGR dispersion between cylinders in an engine test bench. In this paper a methodology using the in-cylinder pressure was developed. The in-cylinder pressure was used to calculate a heat release law and combustion parameters that were used to analyze the EGR dispersion between cylinders. Engine test measurements at three different engine speeds and with three different HP-EGR configurations were performed in order to assess the developed analysis methodology. NOx emissions and fuel consumption were also compared between the different HP-EGR configurations to complete the analysis. The developed methodology was successfully used in three different operating conditions for three different HP-EGR configurations, showing the relation between the decrease in EGR dispersion between cylinders and the decrease in NOx emissions, while maintaining and, in some points, improving the fuel consumption.
\end{abstract}

Keywords: EGR, diesel engine, EGR dispersion, high pressure EGR, NOx emissions, fuel consumption 


\section{Introduction}

The development of current diesel engines is focused on lowering fuel consumption and pollutant exhaust emissions. Since pollutant emission regulations have become more restrictive, new technologies have been developed. Currently, EGR continues to be employed as a technique to reduce NOx. As NOx emissions become more stringent, the EGR rates increase and strategies using mixed EGR loops (high pressure and low pressure) are implemented in current engines, in some of these research works can be appreciated [1-3].

The introduction of exhaust gases in the combustion chamber inhibits the creation of NOx emissions by reducing the peak combustion temperature and decreasing the oxygen concentration as it was found in these research works [4-7]. High pressure (HP) EGR loops were used since the beginning to introduce EGR into the engine decreasing the NOx emissions but penalizing the fuel consumption, as it was found by Kohketsu et al. in their research work [8]. On the other hand low pressure (LP) EGR loop systems are effective means of simultaneously reducing the NOx emission and fuel consumption of diesel engines. Current diesel engines are using both HP-EGR and LP-EGR loops, to maximize the reduction of NOx emissions and minimize the fuel consumption. Langridge et al. studied different high EGR strategies for Diesel engines using LP and HP EGR loop configurations [9].

HP-EGR systems effects such as the non-homogeneous EGR distribution between cylinders, which were neglected before, are very important in current diesel engines. This phenomenon has been studied by different researchers since the introduction of the system. In [10], Payri et al. use a $\mathrm{CO}_{2}$ probe to determine the EGR dispersion between cylinders and a similar idea was performed by Partridge et al. who used a capillary inlet mass spectrometer to measure the EGR for each cylinder [11]. In [12], Maiboom et al. analyze the influence of the EGR dispersion over NOx and PM emissions trade off, changing the mixing intake conditions. A similar study was performed by Lakhlani et al. in their research work [13], to study the NOx-PM trade off deterioration due to the EGR dispersion between cylinders. In [14] Green et al. measured EGR distribution using an optical diagnosis based on infrared-absorption spectroscopy. Siewert et al. developed a methodology to minimize EGR dispersion using CFD as a modelling tool to improve the intake mixing and then engine testing to compare the exhaust emissions for each configuration [15]. A CFD technique was also used by Nandi et al. [16] because they found that the available testing techniques were inadequate to make measurements of the actual EGR distribution. 
These previous investigations encourage further research efforts to develop new measurement methodologies to analyze the EGR dispersion between cylinders while using a HP-EGR system. The developed methodology is a non-intrusive method to avoid any geometry modifications to the intake manifold configuration that can modify the EGR dispersion between cylinders, that is the case when using $\mathrm{CO}_{2}$ probes or capillary inlet mass spectrometers. Furthermore there is no uncertainty about the placement of any device.

The methodology uses in-cylinder pressure measurements in the four cylinders and a combustion analysis model. The HP-EGR combustion results are normalized using LPEGR tests that match the same intake manifold conditions, in order to analyze the EGR dispersion between cylinders. An intake manifold with an integrated water-air intercooler was tested with three different internal plates to achieve different HP-EGR distribution between cylinders at three different engine operating conditions.

The paper is structured as follows: In section 2 the experimental setup is explained. Section 3 is devoted to the explanation of the methodology used in order to obtain accurate and useful results. Section 4 contains main results and discussion in terms of combustion, NOx emissions and fuel consumption. Finally, main conclusions are presented in section 5 .

\section{Experimental Setup}

The experiments were performed on a turbocharged diesel engine which is EURO5 compliant. Main characteristics of the engine are given in Table 1. The engine has a HP-EGR loop with an EGR cooler placed in order to reduce the EGR temperature before the EGR valve and intake manifold. The integrated intake/intercooler manifold is placed upstream the HP-EGR valve, with the EGR inlet tube on the side of the plenum as can be seen in Figure 1. The lateral EGR inlet on the intake plenum produces a high dispersion between cylinders; different plates, designed to modify the flow patterns in the manifold, were tested in order to decrease the EGR dispersion. These plates are the preliminary results of a CFD optimization of the distribution of the EGR among the engine cylinders, performed by the industrial partner of this study. The design of the mentioned plates is presented in Figure 2, where the cross section of the holes is depicted. The exhaust gases have to pass through these holes to enter into the eight intake pipes and mix with the fresh air. Plate \#A shows a regular pattern for the holes in each cylinder while the configuration of the holes in plate \#B presents very different cross section values depending on the intake pipe of each cylinder. 
The engine is also equipped with a custom made LP-EGR loop, located downstream the diesel particle filter (DPF) and before the compressor inlet. An EGR cooler is used to prevent excessive temperatures on the compressor inlet. In addition, a backpressure valve placed in the exhaust line downstream the EGR extraction can be used to allow higher EGR rates. A schematic engine layout is shown in Figure 3.

The engine was fully instrumented and installed in a dynamic test rig. In-cylinder pressure signals from each cylinder were recorded using a Kistler 6961A250 piezoelectric transducer integrated in the glow plug. The crank-angle signal was measured using a Kistler crank-angle encoder type 2613A with its proper Kistler signal conditioner. The top dead center (TDC) was determined based on the Hohenberg proposal [17], and a detailed description can be found in Benajes et al. [18]. The intake $\mathrm{CO}_{2}$ concentration and exhaust gas emissions ( $\mathrm{NOx}, \mathrm{HC}, \mathrm{CO}, \mathrm{CO}_{2}$ and $\mathrm{O}_{2}$ ) were measured by a Horiba Mexa 7100 DEGR. Intake and exhaust $\mathrm{CO}_{2}$ concentrations have been measured by a non-dispersive infrared analyzer (NDIR), while exhaust NOx concentration is measured by means of heated chemiluminiscent detector (HCLD). The EGR rate was obtained experimentally from the $\mathrm{CO} 2$ measurements in exhaust and intake manifolds according to the expression used by Payri et al. in their research work [11]:

$$
\text { EGRrate }=\frac{\left[\mathrm{CO}_{2}\right]_{\text {Intake }}-\left[\mathrm{CO}_{2}\right]_{\text {Ambient }}}{\left[\mathrm{CO}_{2}\right]_{\text {Exhaust }}-\left[\mathrm{CO}_{2}\right]_{\text {Ambient }}}
$$

Using an intercooler able to control the intake manifold temperature and a variable geometry turbine (VGT) to control the compressor compression ratio, it is possible to achieve similar intake manifold conditions in terms of pressure and temperature with HP-EGR and LP-EGR systems, in order to perform the engine tests to compare the HP-EGR dispersion between cylinders.

\section{Methodology}

\subsection{Experimental tasks}

In the present work, the assessment of the EGR distribution among cylinders will be limited to steady engine operation. In transient conditions, other phenomena such as EGR transport along the pipes should be considered and fall beyond the scope of the present study. Three engine running conditions in steady operation were tested in order to provide representative conclusions. The operating conditions were picked from 
engine operation during the NEDC cycle. A chart engine torque versus engine speed is plotted in Figure 4, where each circle represents one second of the homologation cycle performed with a familiar sedan vehicle. Each circle has a certain level of transparency so, by simple inspection of the plot, it is easy to detect in the darker zones the set of torque-speed values where the engine is running during longer periods. Taking into account this information as well as the EGR rate in each condition, three engine steady operations were selected. The engine conditions of points $A, B$ and $C$ are presented in Table 2, with the EGR rate and the vehicle speed in the NEDC cycle. It is observed that the EGR rate is different in each point. They were chosen at different engine speeds to obtain different acoustic behavior of the flow inside the intake manifold.

The experimental procedures are performed by the following three stages. The tests in the first stage are carried out without EGR. Moreover, the engine was operated without and with combustion. With this approach it is possible to certify if there was any dispersion or anomaly between cylinders beyond the EGR strategy. Instantaneous incylinder pressure was measured for both test campaigns. In the upper plot in Figure 5, where the tests without combustion are depicted, no dispersion between cylinders is observed, and a similar compression ratio for every cylinder is detected. On the other hand, in the lower plot, which contains the tests with combustion, certain dispersion between cylinders is observed. The dispersion is caused by the injectors and for this reason comparing cylinders with each other will not provide any meaningful information about EGR dispersion. Therefore, comparisons can only be performed between the same cylinder under different configurations but not between different cylinders in the same configuration.

In a second step, HP-EGR tests are performed at each operating point (A, B and C) with the three EGR plate configurations. Cycle-average engine parameters such as intake temperature and pressure, air mass flow, and EGR rate were acquired. Instantaneous in-cylinder pressure in each cylinder was also measured to perform the combustion analysis. The combination of three engine steady conditions, three EGR plates and four cylinders provides 36 cases for the determination of the in-cylinder heat release rate during the combustion process.

The last stage of the developed methodology consists in repeating the tests with the same engine running conditions and EGR plate configurations but using the LP-EGR loop. It is important to remark that the same intake manifold conditions (temperature and pressure), air mass flow and EGR rate as in the HP-EGR tests have to be achieved. This is accomplished by calibrating the variable geometry turbine position 
and the heat transfer in the intercooler to control the intake pressure and temperature respectively. Again, instantaneous in-cylinder pressure was also measured to perform the combustion analysis in every cylinder, which leads to 36 additional cases for LP configuration.

It is worth noting that we included the combination of the HP-EGR plate in the LP tests, although there is not HP-EGR flow through the plates. In this way, the layout of the intake manifold is identical to the HP tests in order to have the internal fluid-dynamics as similar as possible. Finally, we remark that injection system settings were kept constant between HP and LP tests.

\subsection{Analytical methodology}

From the experimental cylinder pressure profile, the heat release rate was calculated by means of a combustion diagnosis model, used by Lapuerta et al. in their research work to perform a estimation of mean thermodynamic properties of the gas in a Diesel engine using in-cylinder pressure measurements [19]. This model applies the first law of thermodynamics along the closed engine cycle, between intake valve closing and exhaust valve opening. It uses the state equation of ideal gas to calculate the mean gas temperature in the chamber. Along with the previous two basic equations, several sub-models are employed to estimate the blow-by flow, the instantaneous volume considering deformations in the combustion chamber, and the heat transfer and the corresponding wall temperatures. An influence of measurement errors and estimated parameters, using the described combustion diagnosis model, was performed by Payri et al. in their research work [20], where a detailed explanation of the equations used in the combustion model can be seen. A most recent research work was also performed by Benajes et al. [18] using this model. In addition a global energy balance in a Diesel engine was performed, using this model, by Payri et al. in their research work [21] in which also the equations used in the combustion diagnosis model to perform this global energy balance are explained.

Using the heat release law, combustion parameters are obtained such as crank angle at $10 \%$ of fuel mass burned (CA10), crank angle at $50 \%$ of fuel mass burned (CA50), crank angle at $90 \%$ of fuel mass burned (CA90) and combustion duration (CD). The EGR dispersion analysis is going to be focused on combustion duration parameter. The combustion duration for the HP-EGR and LP-EGR configurations is calculated using:

$$
C D_{i}=C A 90_{i}-C A 10_{i}
$$


where $i$ is the cylinder number. In order to evaluate if a cylinder is receiving more or less EGR on the HP-EGR configuration, the HP-EGR tests are going to be compared with the LP-EGR tests since in this configuration all cylinders have equal EGR distribution.

A normalized combustion duration (NCD) parameter is calculated in order to compare each cylinder in the HP and LP EGR configurations. The normalized combustion duration is calculated using the combustion durations of the cylinder in LP-EGR and HP-EGR as:

$$
N C D_{i}=\frac{C D_{i, H P}-C D_{i, L P}}{C D_{i, L P}}
$$

This equation is basically based on the knowledge that the combustion duration is enlarged when more EGR is added since the injected fuel mass, and intake conditions are not changing. Lower oxygen concentration leads to lower combustion rate and in consequence longer combustion durations. Positive values indicate that the cylinder is receiving more EGR in the HP-EGR configuration than in the LP-EGR configuration, while negative values mean the opposite.

Comparing the results for the three different intake plate configurations, it could be determined if the EGR dispersion has an important effect on NOx emissions and fuel consumption.

\section{Results and discussion}

Using the test procedure explained on the methodology section it is possible to analyze the EGR dispersion between cylinders. Results are provided in the following subsections for the different engine operating conditions.

\subsection{Point A}

Heat release law graphs are presented in Figure 6. Each plot shows the heat release function for the three different plate configurations: without plate, \#A and \#B plates. Results from cylinder 1 to 4 are plotted from top to bottom graphs in the figure. Graphs on the left show the evolution from TDC (0 CAD) to 50 CAD after TDC, while a zoom of the results is shown on the right side. Finally, in Table 3 the HP-EGR and LP-EGR combustion duration are given. 
In case of cylinder \#1, using the plate \#A and without plate configuration, the results showed almost the same heat release curve. In terms of combustion duration there is less than a CAD of difference, explaining the similarity between heat release law curves. In the other hand using plate $\# \mathrm{~B}$ a faster combustion rate is observed and a difference of 3 CAD less on combustion duration than with the plate \#A configuration is observed.

After seeing the results, it can be appreciated that using the plate \#B leaves cylinder \#1 with less EGR than with the plate \#A and without plate configuration, because of the shorter combustion and the faster combustion rate observed in the heat release curve.

For cylinder \#2, there is no difference between the heat release law curves for the different plate configurations. Combustion durations are almost identical for the three plate configurations. Therefore, changing the plate configuration did not affect the quantity of EGR in cylinder 2 for this operating point.

For cylinder \#3, the 'without plate' configuration shows the slowest combustion duration and the lowest heat release curve. The plate \#A offers a faster combustion and a heat release curve that is above the without plate configuration. The plate \#B configuration presents the fastest combustion duration and the heat release curve is above the other two configurations. The difference in combustion duration between the slowest and fastest combustion is around $3 \mathrm{CAD}$. In conclusion with the plate \#B configuration less EGR is entering into cylinder \#3.

For cylinder \#4, using the without plate configuration seems to have the fastest combustion compared to the other two configurations, being the plate \#B the configuration that has the slowest combustion and the lowest heat release curve. Plate \#B is the configuration that allows more EGR in cylinder \#4.

Figure 7 presents the normalized combustion duration between all the four cylinders and different plate configurations which is calculated using equation [3] and plotted in percentage scale. Results from left to right correspond to the configuration without, \#A and \#B plates, respectively. For each configuration, results are plotted for all the cylinders. The plate \#B seems to offer the best result, having less EGR dispersion between cylinders than the other two plate configurations.

Figure 8 presents the NOx raw emissions and fuel consumption for the different configurations. Using the plate \#B configuration to reduce the EGR dispersion, the NOx emissions were reduced in $20 \%$ compared to the without plate configuration. It can be also observed that using the plate \#A configuration NOx emissions already were highly 
reduced compared to the without plate configuration, which means that cylinder 4 was the main cause of the NOx emissions because of the lower EGR percentage that was running with the without plate configuration, as it was seen in Figure 7.

On the other hand the fuel consumption did not change between the different plates configurations. Despite the higher EGR rate observed in cylinder 1, 2 and 3 with the original setup (without plate), compared to the other plates configuration, the fuel consumption did not change because the cylinder 4 operated with less EGR producing more NOx but with a higher thermal efficiency that compensated the fuel consumption of the other three cylinders.

\subsection{Point B}

The calculated heat release in each cylinder for the HP-EGR configuration with the three different plate configurations is used to perform the analysis. Heat release laws are presented in Figure 9. The layout of this figure is the same as the previously described in Figure 6. Finally, in Table 4 the HP-EGR and LP-EGR combustion duration are given.

In cylinder \#1, using the \#A and without plate configuration, the combustion results showed almost the same heat release curve, as it also occurred in point $A$. In terms of combustion duration there is less than a 0.5 CAD of difference, explaining the similarity between heat release curves. Using the plate \#B configuration a faster combustion rate is observed, providing a heat release curve that is above the other two configurations, and a difference of around 1.5 CAD less on combustion duration than with the without plate' configuration. The plate $\# \mathrm{~B}$ configuration has the fastest combustion meaning that there is less EGR in the cylinder compared to the other two configurations.

In cylinder \#2, the plate \#B configuration has the slowest combustion rate, in consequence the longest combustion and the lowest heat release curve as observed in Figure 9. This leads to conclude that the plate allows more EGR in the cylinder than the other two configurations. The combustion duration is almost 1 CAD longer than the fastest combustion, obtained using the plate \#A configuration. The \#A and without plate configuration have almost the same heat release law curve and a 0.2 CAD of difference between the combustion duration.

Concerning cylinder \#3, the \#B plate configuration has the fastest combustion rate and in consequence the highest heat release curve and the shortest combustion duration compared to the other two configurations. In this cylinder a big difference between the different plate configurations can be observed. The configuration without plate has the 
slowest combustion rate, lowest heat release law curve and longest combustion duration, meaning that allows more EGR into the cylinder compared to the other two configurations.

In cylinder \#4 the 'without plate' configuration has the fastest combustion rate, highest heat release curve and shortest combustion duration compared to the other two configurations. A difference of more than $4 \mathrm{CAD}$ in combustion duration is detected between the without plate configuration and the plate \#B configuration. As it also occur in point $A$, the plate \#B configuration increased the EGR in cylinder \#4 compared to the other two plate configurations.

Figure 10 presents the results of the normalized combustion duration. The value for cylinder \#4 without plate exceeds $-9 \%$, which means that the combustion duration in this cylinder is $9 \%$ slower than what it is obtained in the LP EGR loop test, having less EGR rate than in the LP-EGR configuration. For \#A and \#B plates results are very similar with values lower than $5 \%$ in absolute values, having less EGR dispersion between cylinders than the without plate configuration.

Figure 11 presents the NOx emissions and fuel consumption for the different configurations. The plate \#B has $2 \%$ less NOx emissions than the plate \#A and a $0.5 \%$ more in fuel consumption. The NOx emissions were reduced in $29-31 \%$ and the fuel consumption in $1-1.5 \%$, compared to the without plate configuration.

\subsection{Point C}

The calculated heat release in each cylinder for the HP-EGR configuration using the three different plate configurations is used to perform the analysis. Heat release laws are presented in Figure 12. The layout of this figure is the same as the previously described in Figures 6 and 9. Finally, in Table 5 the HP-EGR and LP-EGR combustion duration are given.

In cylinder $\# 1$, using plate $\# B$ and without plate configurations showed similar heat release rate curves. In terms of combustion duration there is less than a 0.8 CAD of difference, explaining the similarity between heat release law curves. Using the plate \#A configuration a slower combustion rate is observed, and a difference of around 1 CAD on combustion duration compared to the without plate configuration. The plate \#A configuration has the slowest combustion duration meaning that there is more EGR in the cylinder compared to the other two configurations.

As for cylinder \#2, the plate \#B configuration has the slowest combustion rate and in consequence the longest combustion and lowest heat release law curve as in point $B$, 
allowing more EGR in cylinder than the other two configurations. The combustion is around 1 CAD longer than the fastest combustion, which was obtained with the plate \#A configuration. The without plate and plate \#A configuration have similar heat release law curves and less than 0.2 CAD of difference between the combustion duration.

The plate \#B configuration has the fastest combustion duration in cylinder \#3. In consequence the heat release curve is higher and shorter compared to the other two configurations, as also shown in point $\mathrm{B}$. The plate \#A and without plate configurations have similar heat release law curves and less than 0.1 CAD difference in combustion duration. The plate \#B has less EGR than the other two plate configurations because of the fastest combustion rate and shortest combustion duration.

In cylinder \#4 the 'without plate' configuration has the fastest combustion rate, highest heat release law curve and smallest combustion duration compared to the other two configurations. A difference of almost 2 CAD in combustion duration was calculated between the 'without plate' and \#A plate configuration, which was the slowest one. Therefore, the cylinder \#4 in the plate \#A configuration receives more EGR compared to the other two plate configurations.

Figure 13 shows that plate \#A seems to offer the best results, having less EGR dispersion between cylinders than the plate $\# \mathrm{~B}$ and without plate configuration. Compared to point $A$ and $B$, in this point $C$ the plate \#A and \#B improve the $E G R$ dispersion compared to the without plate configuration but there is still a EGR dispersion as it can be observed in the figure. This could be due to acoustic phenomena at the intake manifold, EGR rate and intake manifold conditions since they are different for each tested operating condition.

The exhaust emissions and fuel consumption for the different plate configurations are presented in Figure 14. The plate \#A has 3\% less NOx emissions than the plate \#B, leaving the \#A as the best choice to reduce the EGR dispersion. Reducing the NOx emissions in $40 \%$ and the fuel consumption in $1 \%$, for this operating point, compared to the without plate configuration.

NOx raw emissions with the configuration without plate in point $C$ are lower than those compared to the operating points $A$ and $B$. For this reason the reduction percentage in NOx emissions is higher than the other two tested operating points. However, the reduction in absolute concentration value is around the same order of magnitude for the three tested operating points. 


\section{Conclusions}

Three different operating points at different engine speeds and EGR rates were tested with three different HP-EGR plate configurations. A normalized combustion duration parameter using LP-EGR tests is introduced on the developed methodology in order to analyze the EGR dispersion between cylinders. The NCD compares the combustion duration for every cylinder between HP and LP-EGR architectures. A direct comparison between cylinders in a given EGR configuration is not possible because of the dispersion related to the injectors. If zero injection dispersion cannot be achieved, a comparison between different cylinders would give false conclusions.

NOx raw emissions were sensitive to the use of different HP plate designs and showed an important improvement when using \#A and \#B plate configurations, which is linked to the reduction in EGR dispersion observed in the normalized combustion duration parameter. However, differences in fuel consumption were negligible.

It was also observed in the case of the operating point $B$ and $C$ that the reduction achieved on the EGR dispersion between cylinders using plate \#A and \#B configuration was lower compared to the operating point $A$. But the reduction in NOx raw emissions was also observed despite the still observed EGR dispersion between cylinders. Reducing the EGR dispersion between cylinders will always reduce NOx raw emissions.

The non-intrusive method and the developed methodology to analyze the EGR dispersion is the main advantage of this approach over the already developed methodologies using $\mathrm{CO}_{2}$ probes or capillary inlet mass spectrometers on the intake manifold that could change the engine head permeability and in consequence EGR dispersion between cylinders, leaving aside the major problem that these already developed methodologies have. 


\section{References}

[1] Maiboom A, Tauzia X, Shah SR, Hétet J-F. Experimental Study of an LP EGR System on an Automotive Diesel Engine, compared to HP EGR with respect to PM and NOx Emissions and Specific Fuel Consumption. (2009) SAE Technical Paper 2009-240138, doi: 10.4271/2009-24-0138.

[2] Zamboni G, Capobianco M. Influence of high and low pressure EGR and VGT control on in-cylinder pressure diagrams and rate of heat release in an automotive turbocharged diesel engine. Applied Thermal Engineering, 51 (2013), pp. 586-96.

[3] Millo F, Giacominetto PF, Bernardi MG. Analysis of different exhaust gas recirculation architectures for passenger car Diesel engines. Applied Energy, 98 (2012), pp. 79-91.

[4] Heywood JB. Internal Combustion Engine Fundamentals. New York: McGraw-Hill; 1988.

[5] Adachi T, Aoyagi Y, Kobayashi M, Murayama T, Goto Y, Suzuki H. Effective NOx Reduction in High Boost, Wide Range and High EGR Rate in a Heavy Duty Diesel Engine. (2009) SAE Technical Paper 2009-01-1438, doi: 10.4271/2009-01-1438.

[6] Osada H, Aoyagi Y, Shimada K, Goto Y, Suzuki H. Reduction of NOx and PM for a Heavy Duty Diesel Using 50\% EGR Rate in Single Cylinder Engine. (2010) SAE Technical Paper 2010-01-1120, doi: 10.4271/2010-01-1120.

[7] Torregrosa AJ, Olmeda P, Martín J, Degraeuwe B. Experiments on the influence of inlet charge and coolant temperature on performance and emissions of a DI Diesel engine. Experimental Thermal and Fluid Science, 30 (2006), pp. 633-41.

[8] Kohketsu S, Mori K, Sakai K, Hakozaki T. EGR Technologies for a Turbocharged and Intercooled Heavy-Duty Diesel Engine. (1997) SAE Technical Paper 970340, doi: 10.4271/970340.

[9] Langridge S, Fessler H. Strategies for High EGR Rates in a Diesel Engine. (2002) SAE Technical Paper 2002-01-0961, doi: 10.4271/2002-01-0961.

[10] Payri F, Lujan J, Climent H, Pla B. Effects of the Intake Charge Distribution in HSDI Engines. SAE Technical Paper, (2010) SAE Technical Paper 2010-01-1119, doi: 10.4271/2010-01-1119.

[11] Partridge WP, Lewis SA, Ruth MJ, Muntean GG, Smith RC, Stang JH. Resolving EGR Distribution and Mixing. (2002) SAE Technical Paper 2002-01-2882, doi: 10.4271/2002-01-2882.

[12] Maiboom A, Tauzia X, Hétet J-F. Influence of EGR unequal distribution from cylinder to cylinder on NOx-PM trade-off of a HSDI automotive Diesel engine. Applied Thermal Engineering, 29 (2009), pp. 2043-50. 
[13] Lakhlani H, Barman J, Rajput K, Goswami A. Experimental Study of EGR Mixture Design and its Influence on EGR Distribution Across the Cylinder for NOx - PM Tradeoff. (2013) SAE Technical Paper 2013-01-2743, doi: 10.4271/2013-01-2743.

[14] Green RM. Measuring the Cylinder-to-Cylinder EGR Distribution in the Intake of a Diesel Engine During Transient Operation. (2000) SAE Technical Paper 2000-01-2866, doi: 10.4271/2000-01-2866.

[15] Siewert RM, Krieger RB, Huebler MS, Baruah PC, Khalighi B, Wesslau M. Modifying an Intake Manifold to Improve Cylinder-to-Cylinder EGR Distribution in a DI Diesel Engine Using Combined CFD and Engine Experiments. (2001) SAE Technical Paper 2001-01-3685, doi: 10.4271/2001-01-3685.

[16] Nandi S, Mulemane A. Evaluating the EGR Distribution Effectiveness of Intake Manifolds by CFD Technique. SAE Technical Paper, (2009), doi: 10.4271/2009-280011.

[17] Hohenberg G. Definition und Eigenschaften des thermodynamischen Verlustwinkels von Kolbenmaschinen. Autmobile Index 4, (1976), pp. 15-21.

[18] Benajes J, Olmeda P, Martín J, Carreño R. A new methodology for uncertainties characterization in combustion diagnosis and thermodynamic modelling. Applied Thermal Engineering, 71 (2014), pp. 389-99.

[19] Lapuerta M, Armas O, Hernández JJ. Diagnosis of DI Diesel combustion from incylinder pressure signal by estimation of mean thermodynamic properties of the gas. Applied Thermal Engineering, 19 (1999), pp. 513-29.

[20] Payri F, Molina S, Martín J, Armas O. Influence of measurement errors and estimated parameters on combustion diagnosis. Applied Thermal Engineering, 26 (2006), pp. 226-36.

[21] Payri F, Olmeda P, Martin J, Carreño R. A New Tool to Perform Global Energy Balances in DI Diesel Engines. SAE Int J Engines, 7 (2014), pp. 43-59. 


\section{List of captions}

Table 1. Engine characteristics.

Table 2. Tested engine operating points. Table 3. Results for point $A$.

Table 4. Results for point $B$.

Table 5. Results for point C.

Figure 1. WCAC, intake manifold and HP EGR packaging.

Figure 2. Design of the plates.

Figure 3. Schematic Engine Layout.

Figure 4. Engine torque vs. engine speed during a NEDC in a sedan vehicle (each circle represents one second)

Figure 5. In-cylinder pressure without (top) and with combustion (bottom).

Figure 6. Heat release laws, without (solid), \#A (dotted) and \#B (dashed) plates for every cylinder in point $A$.

Figure 7. Normalized combustion duration for the different plate configurations in point A.

Figure 8. NOx raw emissions and brake specific fuel consumption for each plate configuration in point $A$.

Figure 9. Heat release laws, without (solid), \#A (dotted) and \#B (dashed) plates for every cylinder in point $B$.

Figure 10. Normalized combustion duration for the different plate configurations in point $B$.

Figure 11. NOx raw emissions and brake specific fuel consumption for each plate configuration in point $B$.

Figure 12. Heat release laws, without (solid), \#A (dotted) and \#B (dashed) plates for every cylinder in point $C$.

Figure 13. Normalized combustion duration for the different plate configurations in point C.

Figure 14. NOx raw emissions and brake specific fuel consumption for each plate configuration in point $C$. 



\begin{tabular}{|c|c|}
\hline Arquitecture & $4 \mathrm{IL}$ \\
\hline Displacement & $1998 \mathrm{~cm} 3$ \\
\hline Bore $x$ Stroke & $85 \times 88 \mathrm{~mm}$ \\
\hline Valves & $4 /$ cylinder \\
\hline Compression Ratio & $18: 01$ \\
\hline Turbocharger & $\begin{array}{c}\text { Garret VNT GT } \\
1749 \mathrm{~V}\end{array}$ \\
\hline EGR & High Pressure Cooled \\
\hline After-treatment & Oxy-Catalyst + DPF \\
\hline Max. Power / speed & $100 \mathrm{~kW}-4000 \mathrm{rpm}$ \\
\hline Max Torque /speed & $320 \mathrm{Nm}-1750 \mathrm{rpm}$ \\
\hline
\end{tabular}

Table 1. Engine characteristics 


\begin{tabular}{|c|c|c|c|c|}
\hline Point & Engine Speed [rpm] & Torque [N.m] & EGR rate [\%] & Speed [km/h] \\
\hline A & 2300 & 105 & 20 & 120 \\
\hline B & 1910 & 80 & 28 & 100 \\
\hline C & 1600 & 40 & 40 & $0-15$ \\
\hline
\end{tabular}

Table 2. Tested engine operating points 


\begin{tabular}{|c|c|c|}
\hline Cylinder 1 & HP EGR & LP EGR \\
\hline Plate configuration & Comb. Duration [CAD] & Comb. Duration [CAD] \\
\hline Without & 45.75 & \multirow{2}{*}{44.00} \\
\hline Plate \#A & 46.48 & \\
\hline Plate \#B & 43.43 & \\
\hline
\end{tabular}

\begin{tabular}{|c|c|c|}
\hline Cylinder 2 & HP EGR & LP EGR \\
\hline Plate configuration & Comb. Duration [CAD] & Comb. Duration [CAD] \\
\hline Without & 46.14 & \multirow{2}{*}{45.50} \\
\hline Plate \#A & 45.73 & \\
\hline Plate \#B & 46.11 & \\
\hline
\end{tabular}

\begin{tabular}{|c|c|c|}
\hline Cylinder 3 & HP EGR & LP EGR \\
\hline Plate configuration & Comb. Duration [CAD] & Comb. Duration [CAD] \\
\hline Without & 40.52 & \multirow{2}{*}{38.50} \\
\hline Plate \#A & 39.22 & \\
\hline Plate \#B & 37.44 & \\
\hline
\end{tabular}

\begin{tabular}{|c|c|c|}
\hline Cylinder 4 & HP EGR & LP EGR \\
\hline Plate configuration & Comb. Duration [CAD] & Comb. Duration [CAD] \\
\hline Without & 40.55 & \multirow{2}{*}{46.00} \\
\hline Plate \#A & 44.01 & \\
\hline Plate \#B & 44.84 & \\
\hline
\end{tabular}

Table 3. Results for point $A$ 


\begin{tabular}{|c|c|c|}
\hline Cylinder 1 & HP EGR & LP EGR \\
\hline Plate configuration & Comb. Duration [CAD] & Comb. Duration [CAD] \\
\hline Without & 43.38 & \multirow{2}{*}{41.89} \\
\hline Plate \#A & 43.79 & \\
\hline Plate \#B & 42.17 & \\
\hline
\end{tabular}

\begin{tabular}{|c|c|c|}
\hline Cylinder 2 & HP EGR & LP EGR \\
\hline Plate configuration & Comb. Duration [CAD] & Comb. Duration [CAD] \\
\hline Without & 44.81 & \multirow{2}{*}{44.17} \\
\hline Plate \#A & 44.61 & \\
\hline Plate \#B & 45.44 & \\
\hline
\end{tabular}

\begin{tabular}{|c|c|c|}
\hline Cylinder 3 & HP EGR & LP EGR \\
\hline Plate configuration & Comb. Duration [CAD] & Comb. Duration [CAD] \\
\hline Without & 42.11 & \multirow{2}{*}{40.85} \\
\hline Plate \#A & 40.3 & \\
\hline Plate \#B & 38.76 & \\
\hline
\end{tabular}

\begin{tabular}{|c|c|c|}
\hline Cylinder 4 & HP EGR & LP EGR \\
\hline Plate configuration & Comb. Duration [CAD] & Comb. Duration [CAD] \\
\hline Without & 37.00 & \multirow{2}{*}{40.85} \\
\hline Plate \#A & 41.05 & \\
\hline Plate \#B & 41.72 & \\
\hline
\end{tabular}

Table 4. Results for point $B$ 


\begin{tabular}{|c|c|c|}
\hline Cylinder 1 & HP EGR & LP EGR \\
\hline Plate configuration & Comb. Duration [CAD] & Comb. Duration [CAD] \\
\hline Without & 33.28 & \multirow{2}{*}{30.50} \\
\hline Plate \#A & 34.25 & \\
\hline Plate \#B & 32.57 & \\
\hline
\end{tabular}

\begin{tabular}{|c|c|c|}
\hline Cylinder 2 & HP EGR & LP EGR \\
\hline Plate configuration & Comb. Duration [CAD] & Comb. Duration [CAD] \\
\hline Without & 32.84 & \multirow{2}{*}{31.50} \\
\hline Plate \#A & 32.73 & \\
\hline Plate \#B & 33.72 & \\
\hline
\end{tabular}

\begin{tabular}{|c|c|c|}
\hline Cylinder 3 & HP EGR & LP EGR \\
\hline Plate configuration & Comb. Duration [CAD] & Comb. Duration [CAD] \\
\hline Without & 30.84 & \multirow{2}{*}{29.50} \\
\hline Plate \#A & 30.91 & \\
\hline Plate \#B & 29.75 & \\
\hline
\end{tabular}

\begin{tabular}{|c|c|c|}
\hline Cylinder 4 & HP EGR & LP EGR \\
\hline Plate configuration & Comb. Duration [CAD] & Comb. Duration [CAD] \\
\hline Without & 29.28 & \multirow{2}{*}{33.50} \\
\hline Plate \#A & 31.21 & \\
\hline Plate \#B & 30.17 & \\
\hline
\end{tabular}

Table 5. Results for point $C$ 


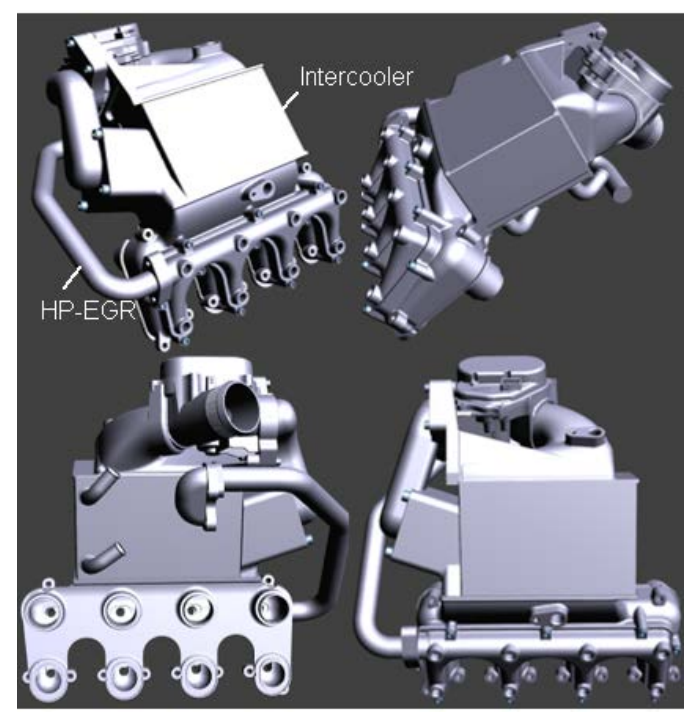

Figure 1. WCAC, intake manifold and HP EGR packaging 

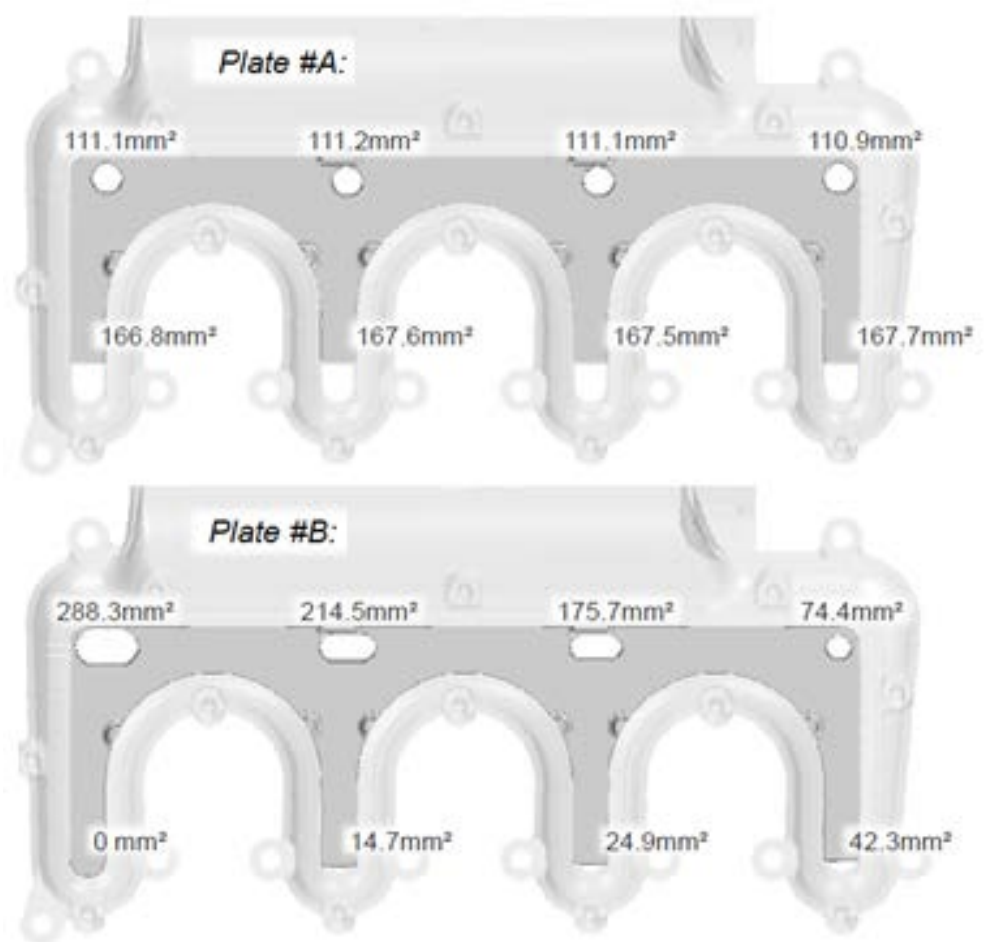

Figure 2. Design of the plates 


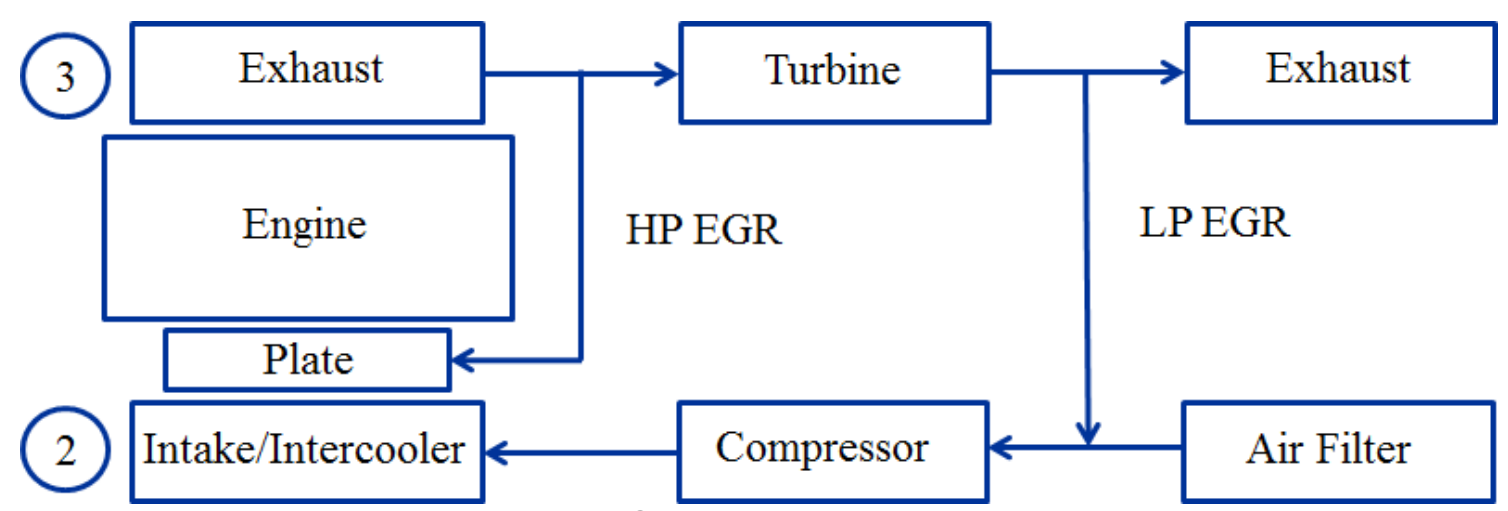

Figure 3. Schematic Engine Layout 


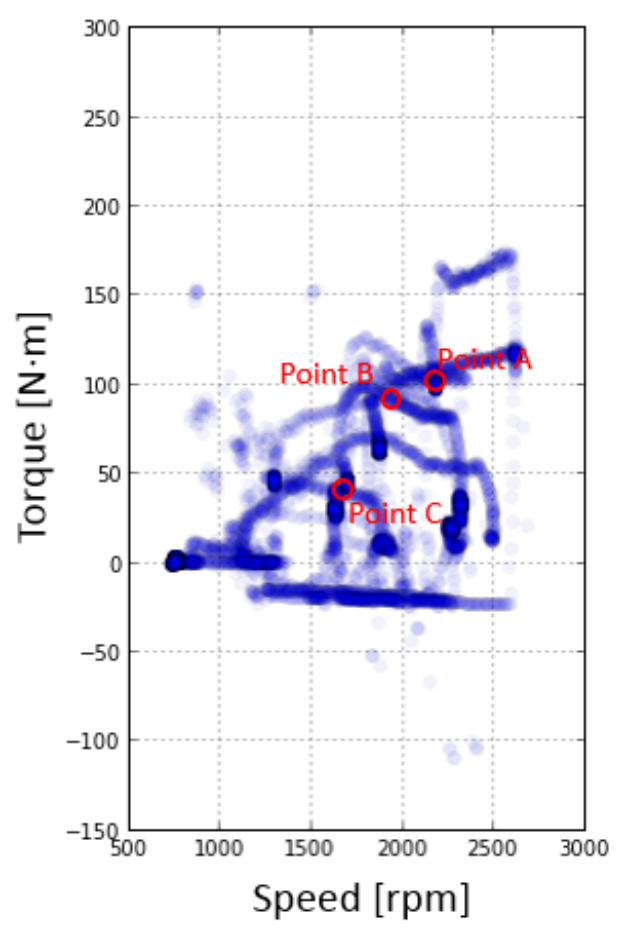

Figure 4. Engine torque vs. engine speed during a NEDC in a sedan vehicle (each circle represents one second) 

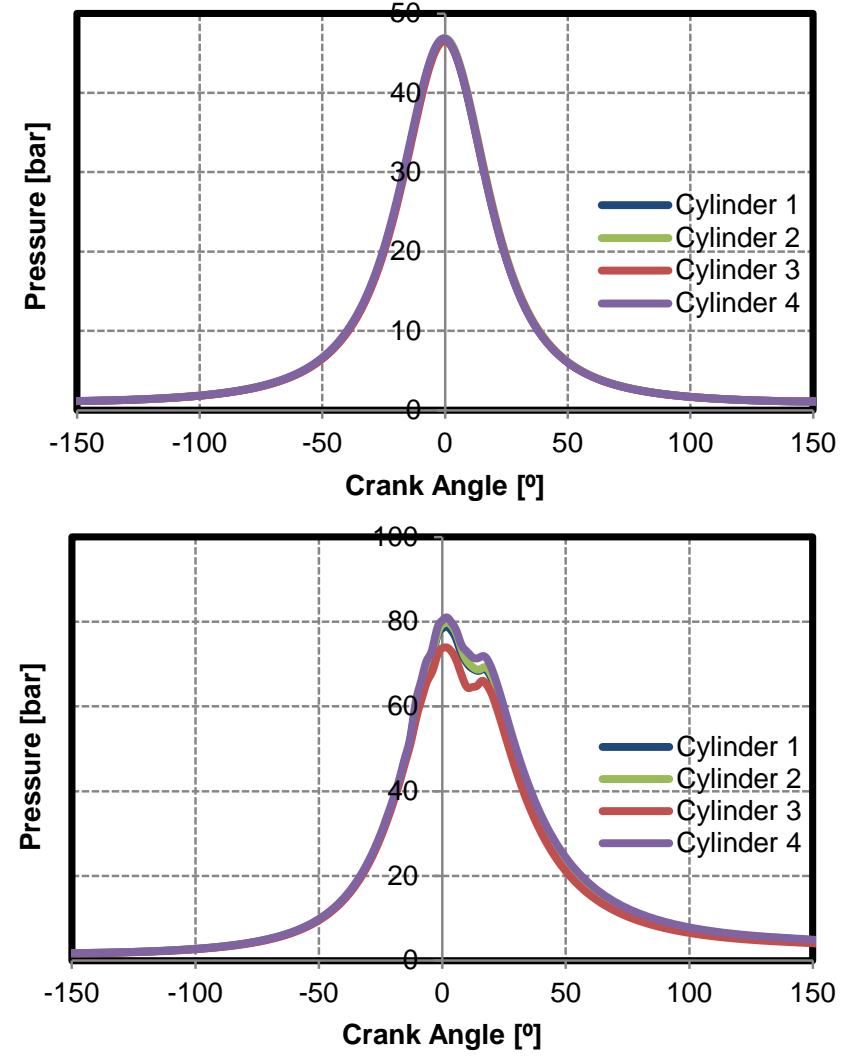

Figure 5. In-cylinder pressure without (top) and with combustion (bottom) 

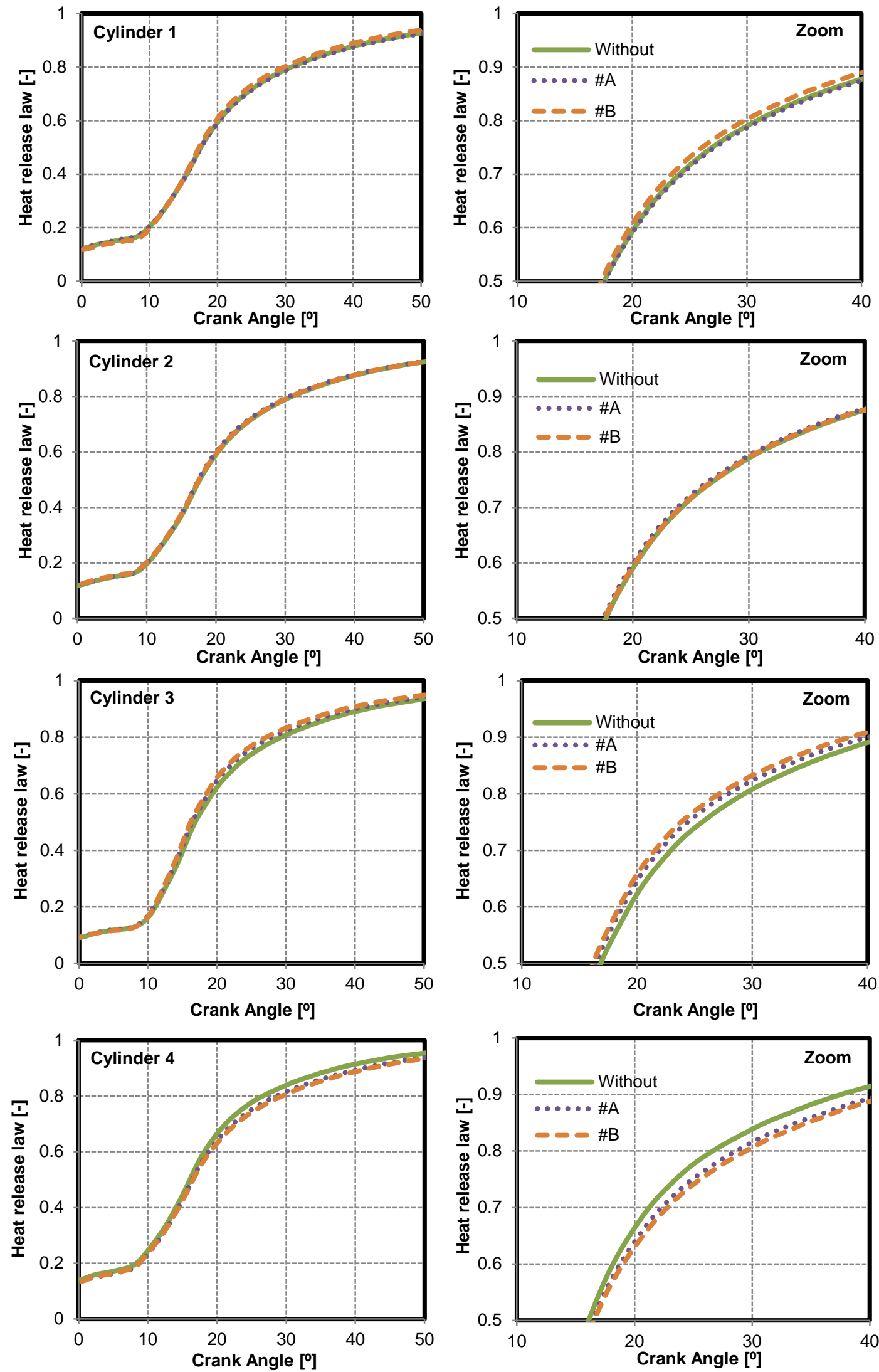

Figure 6. Heat release laws, without (solid), \#A (dotted) and \#B (dashed) plates for every cylinder in point $A$ 


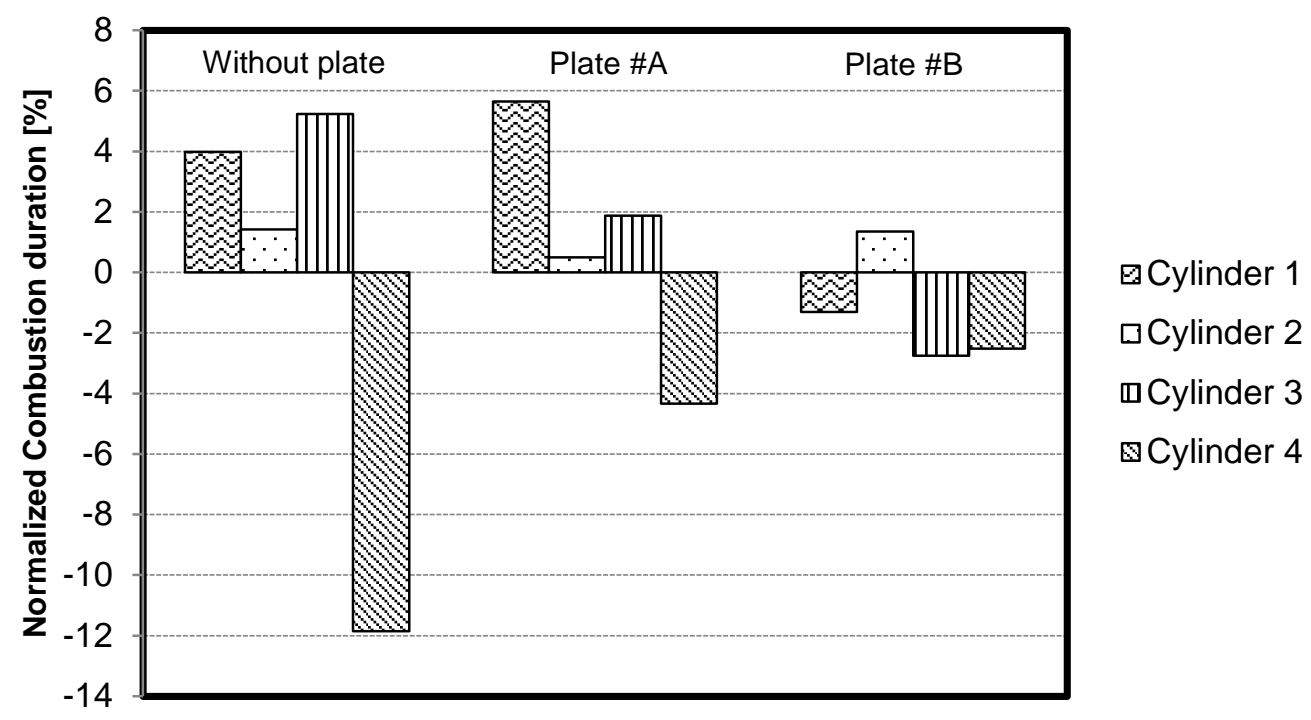

Figure 7. Normalized combustion duration for the different plate configurations in point A 

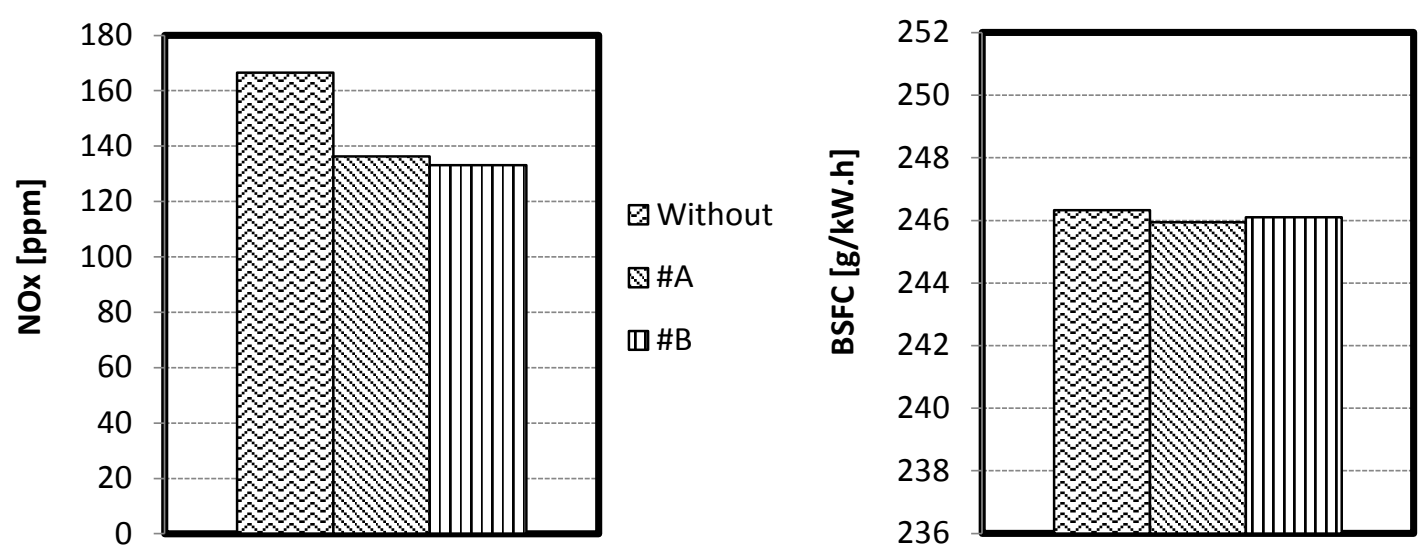

Figure 8. NOx raw emissions and brake specific fuel consumption for each plate configuration in point $A$ 

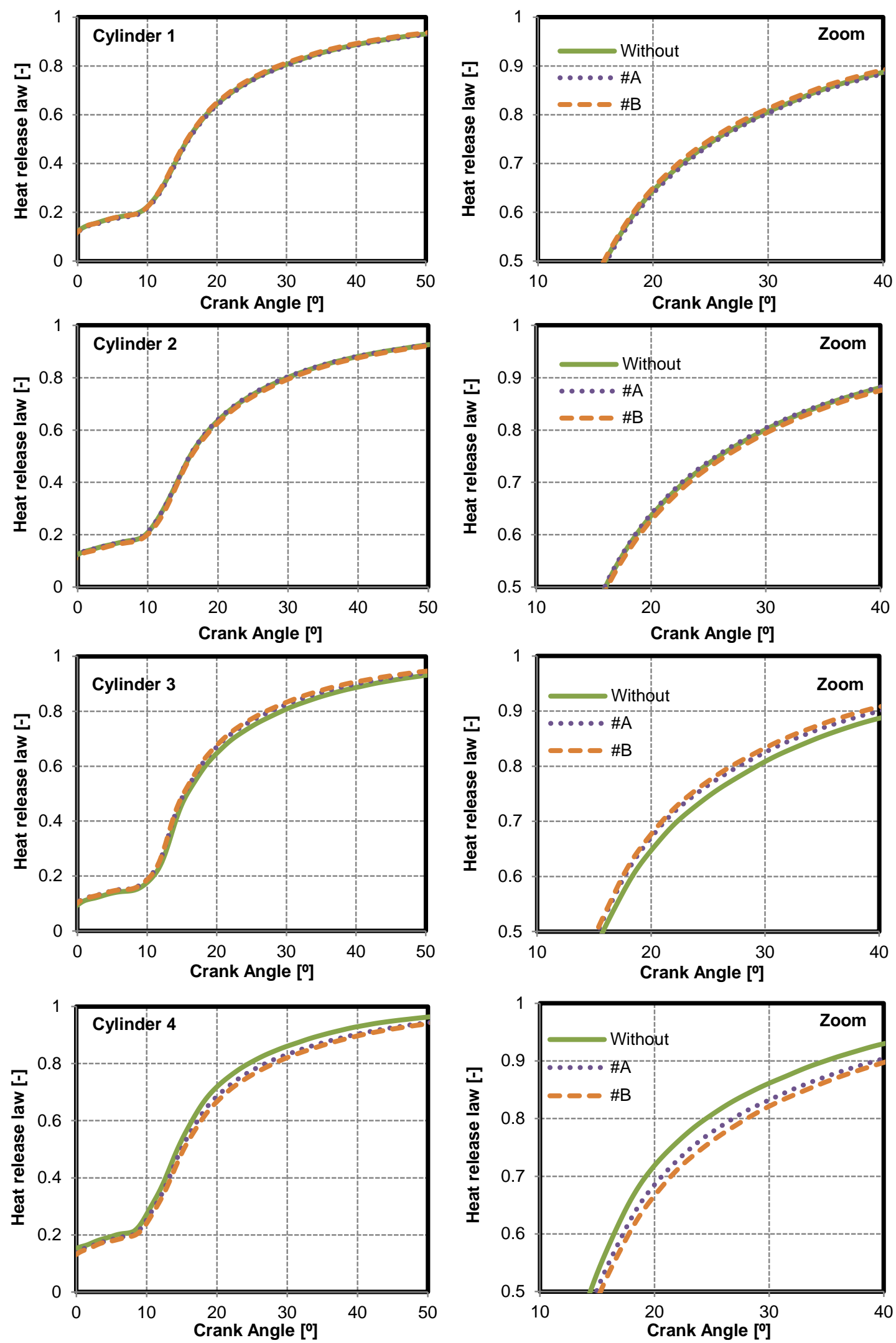

Figure 9. Heat release laws, without (solid), \#A (dotted) and \#B (dashed) plates for every cylinder in point $B$ 


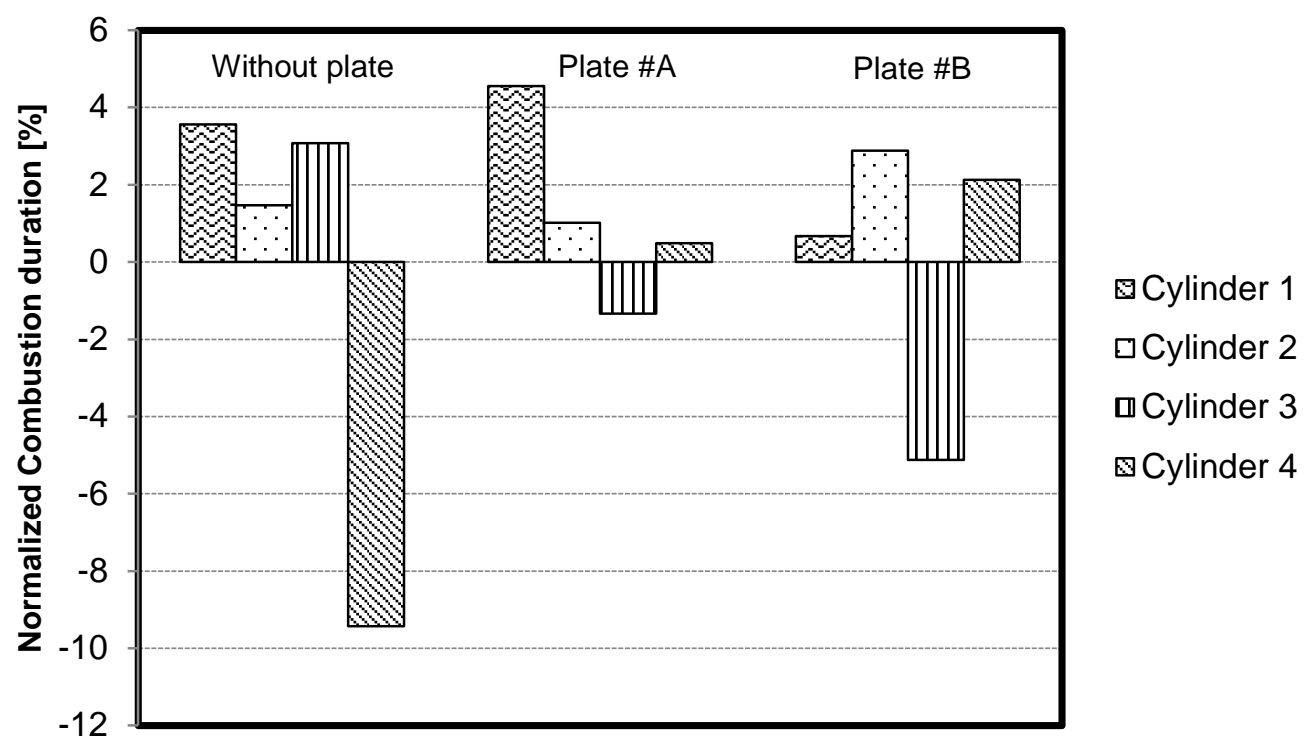

Figure 10. Normalized combustion duration for the different plate configurations in point B 

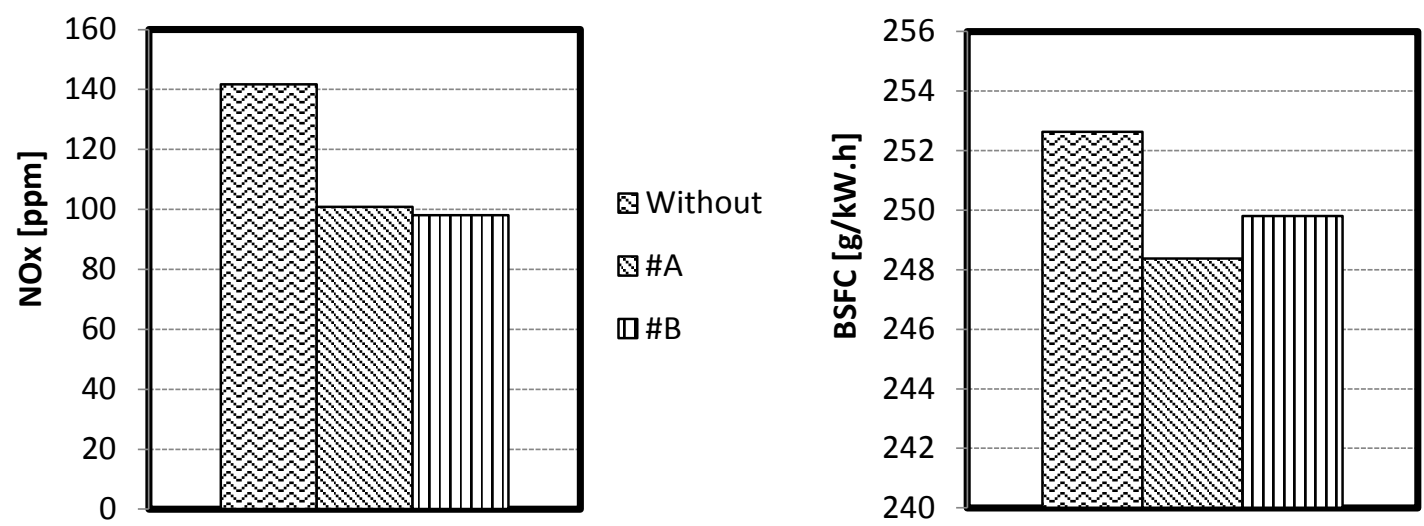

Figure 11. NOx raw emissions and brake specific fuel consumption for each plate configuration in point $B$ 

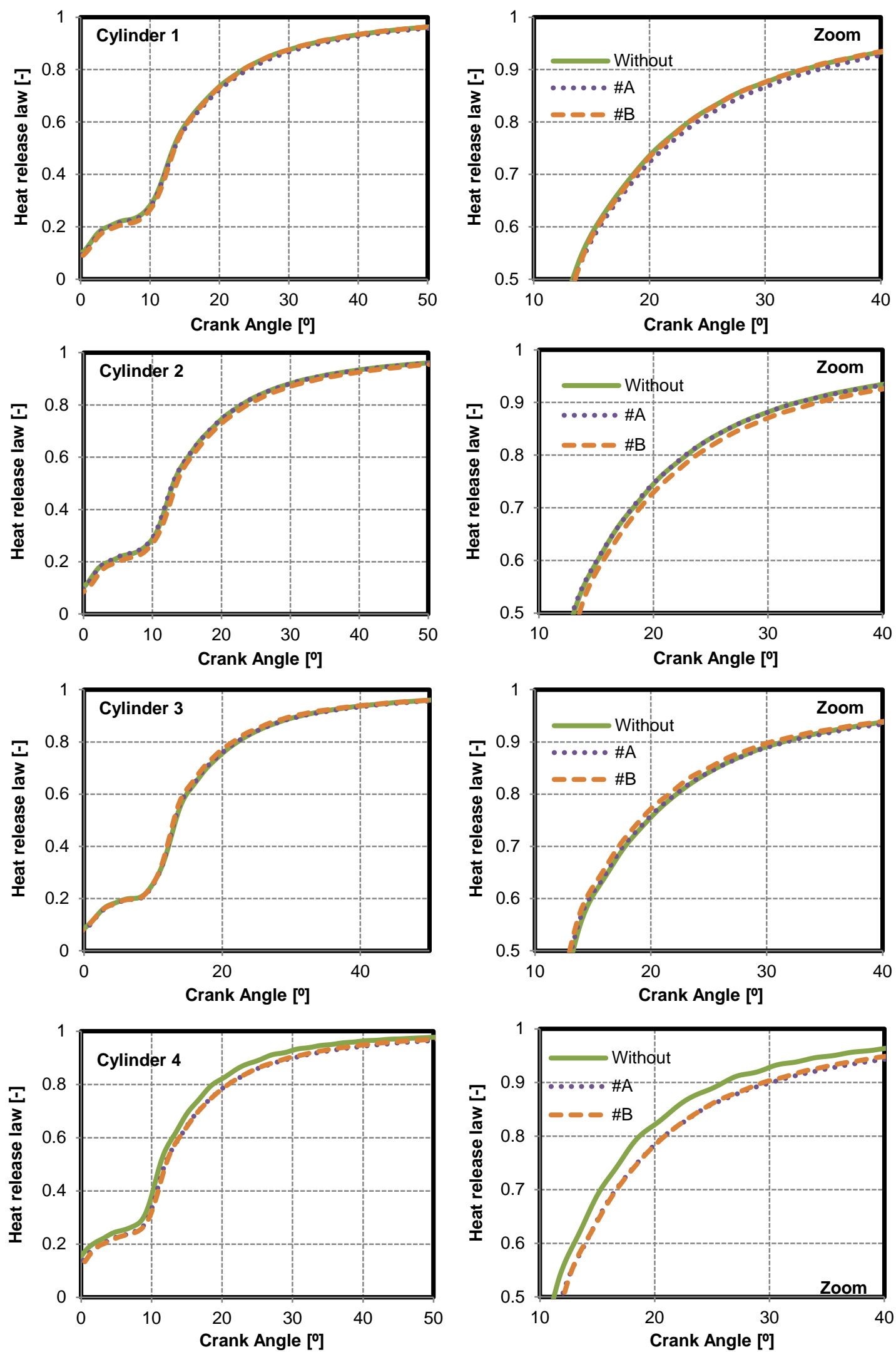

Figure 12. Heat release laws, without (solid), \#A (dotted) and \#B (dashed) plates for every cylinder in point $C$ 


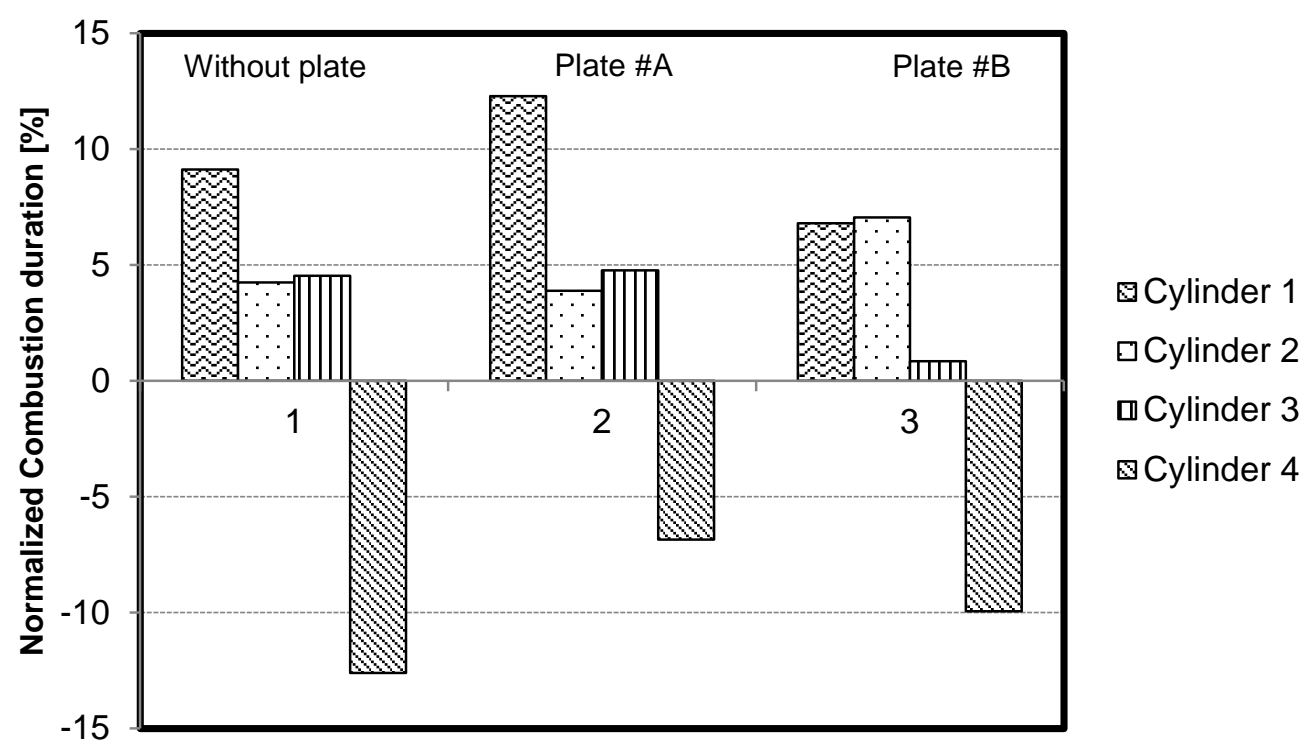

Figure 13. Normalized combustion duration for the different plate configurations in point C 

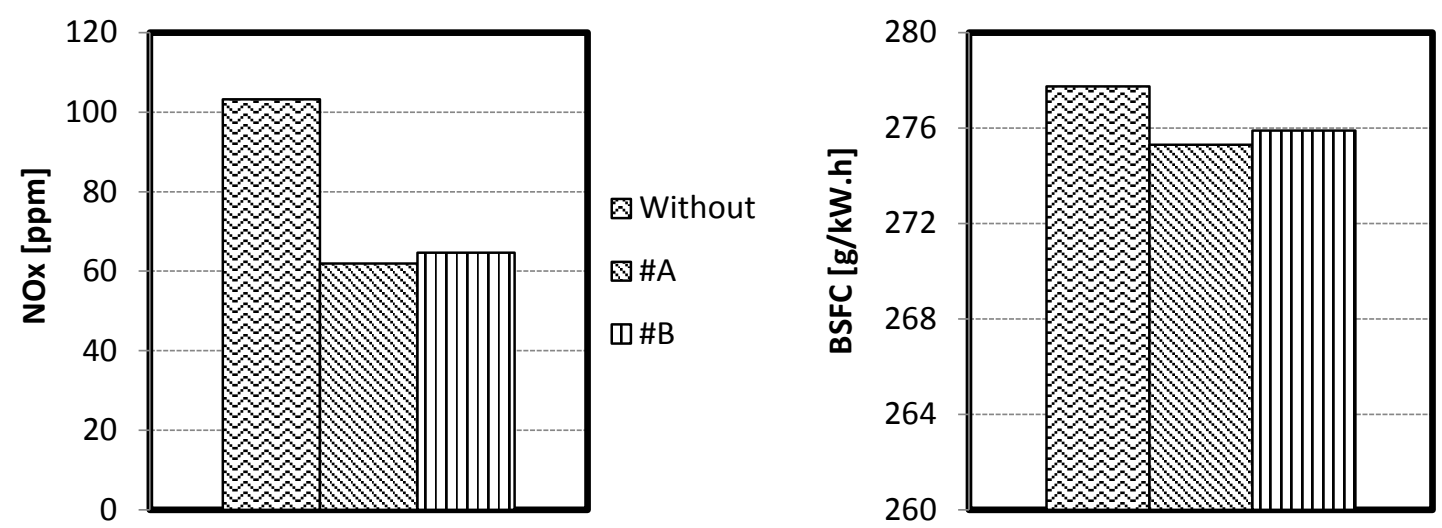

Figure 14. NOx raw emissions and brake specific fuel consumption for each plate configuration in point $C$ 